\title{
Itraconazole Oral Solution for a Case of Infantile Hemangioma: Monitoring the Efficacy by Dermoscopy and MRI
}

\author{
Ying Huang $\cdot$ Xin Ran $\cdot$ Xiaoxi Xu $\cdot$ Sushmita Pradhan (1) · \\ Jiayu Sun $\cdot$ Hehan Tang $\cdot$ Yuping Ran (1)
}

Received: May 26, 2021 / Accepted: July 3, 2021 / Published online: July 24, 2021

(c) The Author(s) 2021

\begin{abstract}
Infantile hemangioma is a common and challenging benign vascular tumor. Although involution is spontaneous, approximately $10 \%$ of infantile hemangioma of large size or in specific locations may cause ulceration, severe cosmetic and functional problems that may require intervention. Treatment options include oral propranolol, topical timolol, and oral corticosteroids. However, the clinical response is not always satisfactory. We report
\end{abstract}

Y. Huang $\cdot$ X. Ran $\cdot$ X. Xu $\cdot$ S. Pradhan $\cdot$ Y. Ran $(\bowtie)$ Department of Dermatovenereology, West China Hospital, Sichuan University, Chengdu, China e-mail: ranyuping@vip.sina.com

Y. Huang

e-mail: huangying1@stu.scu.edu.cn

X. Ran

e-mail: ranfjk@126.com

$\mathrm{X} . \mathrm{Xu}$

e-mail: 2017324025162@stu.scu.edu.cn

S. Pradhan

e-mail: 1197597473@qq.com

J. Sun $\cdot$ H. Tang $(\bowtie)$

Department of Radiology, West China Hospital, Sichuan University, Chengdu, China

e-mail: lanny.320@163.com

J. Sun

e-mail: sjy080512@163.com the case of a 4-month-old boy who presented with an irregular erythematous plaque on his left shoulder 3 days after birth. Infantile hemangioma was diagnosed. Topical application of $0.5 \mathrm{ml}$ of $0.5 \%$ timolol maleate eye drops for half an hour each time three times a day was initiated. After nearly 3 months of follow-up, the size of the lesion gradually increased. Finally, after 115 days of treatment with itraconazole oral solution (the total dose was about $4025 \mathrm{mg}$ ), the refractory infantile hemangioma was successfully treated. Hepatic and renal function remained normal with only mild diarrhea during the course of oral medication. Treatment compliance of oral itraconazole in infants has been reported to be good. Dermoscopy and magnetic resonance imaging (MRI) played a crucial role in in vivo observation of the hemangioma changes with vascular regression during the treatment process.

Keywords: Infantile hemangioma; Itraconazole oral solution; Dermoscopy; Magnetic resonance imaging 


\section{Key Summary Points}

A 4-month-old boy presented with an irregular erythematous plaque on his left shoulder 3 days after birth. Infantile hemangioma was diagnosed. We report a case failure to topical application of timolol maleate eye drops successfully treated by itraconazole oral solution.

Due to the high compliance of infants during the treatment, oral itraconazole played an effective complementary therapy to serve infantile hemangioma.

Dermoscopy played a crucial role in in vivo accurate observation of the hemangioma changes with vascular regression during the treatment process. MRI played a vital role in diagnosis and monitoring of the therapeutic process.

\section{INTRODUCTION}

Infantile hemangioma (IH) is known as the most common benign vascular tumor of childhood. IH occurs more frequently in female infants, with $5-10 \%$ incidence during the first year of life [1], with prematurity, low birth weight, and placental anomalies appearing to be the most significant risk factors [2]. Their pathogenesis remains unknown. Since 2009, topical beta-blockers have been widely used in the clinical treatment of $\mathrm{IH}$, among which $0.5 \%$ timolol maleate eye drops are commonly used [3]. Itraconazole (ICZ), an active triazole antifungal drug, has recently been found to possess antiangiogenic and anti-hedgehog activity. Our team had previously reported case series on the therapeutic effects of ICZ capsules on IH [4]. We herein report a case of ineffective topical application of timolol maleate eye drops treated successfully with ICZ oral solution. Dermoscopy and MRI may play a vital role in diagnosis and monitoring of treatment.

\section{CASE PRESENTATION}

A 4-month-old boy presented with an irregular erythematous plaque on his left shoulder 3 days after birth. The lesion gradually turned brighter, progressive, and enlarged into an elevated erythematous plaque. Clinical diagnosis was consistent with IH. Topical application of $0.5 \mathrm{ml}$ of $0.5 \%$ timolol maleate eye drops for half an hour each time three times a day was initiated. After nearly 3 months of the treatment, the lesion became bigger. The infant was born full-term, weighing $3.9 \mathrm{~kg}$ without any complications. Physical examination revealed a nonblanchable erythematous plaque of approximately $2.6 \times 2.4 \mathrm{~cm}$ size on the left shoulder (Fig. 1A1). Dermoscopic examination showed an intensive vascular network (Fig. 1B1). MRI examination accorded with the diagnosis of IH (Fig. 2A). The patient's mother gave informed consent and was counseled about the benefits and possible adverse effects before initiating the treatment. The patient weighed $7 \mathrm{~kg}$, and the daily dosage calculated at $5.0 \mathrm{mg} / \mathrm{kg} /$ day was $35 \mathrm{mg}$, equal to $3.5 \mathrm{ml}$ ICZ oral solution (Sporanox) (Janssen, $\mathrm{Xi}$ 'an, China). Using a syringe without a needle, $3.5 \mathrm{ml}$ of the oral solution was withdrawn and fed orally to the child. The parents were provided a form to record the actual dosage and adverse reactions during the course of the treatment. After 115 days of treatment, the skin lesion turned flat and significantly reduced in size, and dermoscopic features showed distinct vascular network and fewer capillary branches (Fig. 1A2, B2), so the treatment was terminated. During the 1 month of follow-up, the lesion was almost cured, with only residual skin erythema left (Fig. 1A3, B3). MRI examination was rescheduled (Fig. 2B). Liver function examination was within normal limit, with only mild diarrhea, which did not affect the continued medication. Until the age of 16 months, no recurrence of hemangioma has been observed.

\section{DISCUSSION}

IH usually forms within the first week after birth and grows rapidly during the first 3-6 months, known as the proliferating phase of $\mathrm{IH}$. 

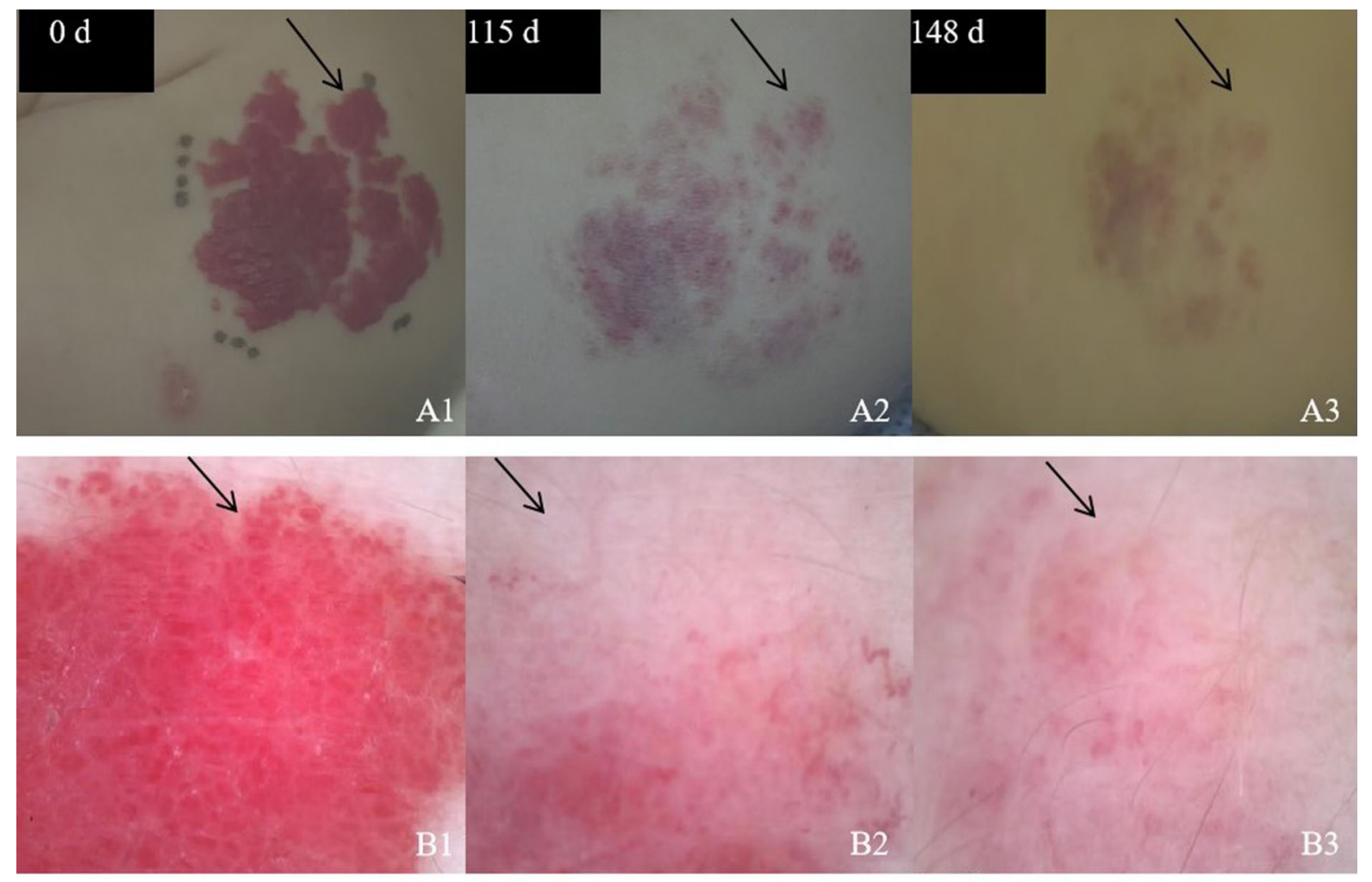

2020.5.11

2020.9.3

2020.10.6

Fig. 1 Clinical response of a 4-month-old boy to oral ICZ solution therapy. Clinical manifestation of the patient observed for the first time (A1, B1). After 115 days of treatment, the lesion significantly improved, the intensive vascular network gradually disappeared during the treatment (amplification $\times 67)($ A2, B2). The latest follow-up showed no recurrence of hemangioma $(\mathbf{A 3}, \mathbf{B 3})$

outcomes in six cases [4]. We found that ICZ induces regression of infantile IH via downregulation of the platelet-derived growth factor-D/ PI3K/Akt/mTOR pathway [13].

In our case, the patient's parents had a strong desire for treatment. After an ineffective treatment outcome with topical application of timolol maleate eye drops for nearly 3 months, he was brought to our hospital. After 1 month, the lesion achieved partial efficacy and almost resolved with remaining skin erythema after nearly 4 months of treatment with ICZ oral solution. Hepatic and renal function remained normal, with only mild diarrhea during the course of oral medication. The infant may be in the proliferative period during treatment with ICZ. Clinical images showed dramatic improvement following ICZ therapy, which is 


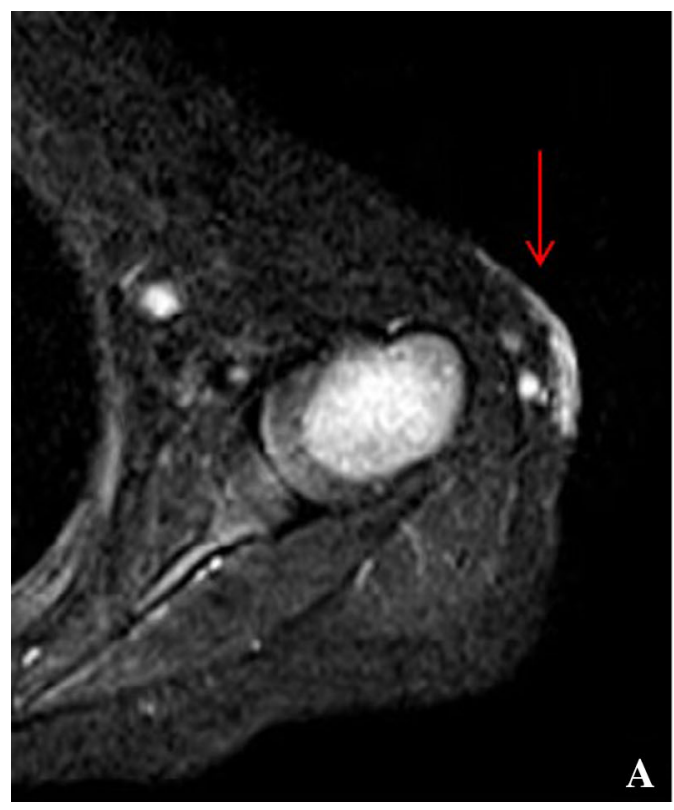

Fig. 2 Time course of the IH changes of MRI monitoring during ICZ oral solution therapy corresponding to the observation of the targets. At the beginning of the treatment: transverse T2-weighted $\mathbf{A}$ images show a mass (arrow) sized $2.2 \times 2.8 \times 0.7 \mathrm{~cm}$ in the lateral aspect of

unlikely due to spontaneous resolution alone. It is convenient to examine liver function before and after treatment with ICZ. Infants may have difficulty swallowing capsules. Furthermore, adjusting the dosages of capsules for children can prove troublesome. One milliliter of ICZ oral solution contains $10 \mathrm{mg}$ of ICZ, which is more accurately measured on the syringe and more convenient than splitting capsule particles. In addition, its cherry flavor makes it more acceptable to infants. Treatment compliance of oral ICZ in infants has been reported to be good. Neither this boy in this case nor the infants in the previous case series reported by our team currently show recurrence of hemangioma. Due to limited data, more clinical trials are needed to be conducted for confirmation. Oral ICZ can be used as a supplementary treatment for IH.

Compared with the naked eye, dermoscopy can observe subtle changes before and after treatment more clearly by adjusting the magnification. At present, there are only a few reports about the dermoscopic characteristics of IH. Meanwhile, MRI can provide additional

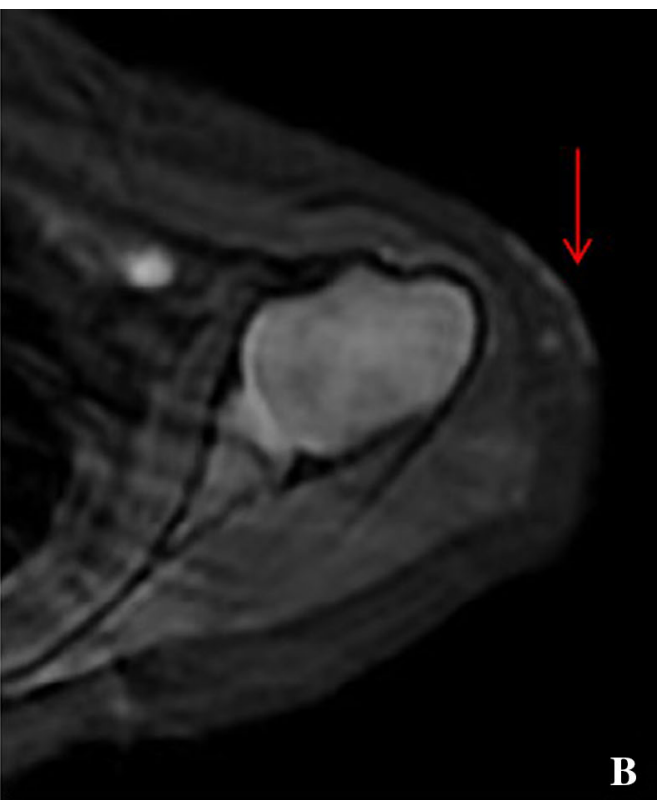

the left upper arm. The latest follow-up: transverse T2weighted $\mathbf{B}$ images reveal the size of mass has shrunk to about $1.5 \times 2.2 \times 0.7 \mathrm{~cm}$

information, such as the extent of the lesion. Several studies have reported on the imaging features of IH on conventional MRI $[14,15]$.

\section{CONCLUSION}

ICZ oral solution can be used as a novel drug for refractory $\mathrm{IH}$ that failed to respond to topical application of timolol maleate eye drops. Dermoscopy and MRI are combined with monitoring the vascular regression of ICZ oral solution before and after the treatment of IH for effective therapeutic evaluation.

\section{ACKNOWLEDGEMENTS}

Funding. This work was supported in part by the Sichuan Science and Technology Program (Grant 2020YFS0194), the National Natural Science Foundation of China (Grant 81472539), 1.3.5 project for disciplines of excellence, West 
China Hospital, Sichuan University and HXAcademician project (HXYS19003), West China Hospital, Sichuan University. The Rapid Service Fee was funded by the authors.

Authorship. All named authors meet the International Committee of Medical Journal Editors (ICMJE) criteria for authorship for this article, take responsibility for the integrity of the work as a whole, and have given their approval for this version to be published.

Authorship Contributions. Writing original draft preparation: Y.H.; patient's follow-up and data collection: X.R., Y.H., X.X., and S.P.; reviewing and editing the manuscript: S.P.; imaging examination: J.S. and H.T.; funding acquisition: X.R. and Y.R. Y.H. and X.R. contributed equally to this study and are co-first authors. Y.R. and H.T. contributed equally to this study and are co-corresponding authors.

Disclosures. Y.H., X.R., X.X., S.P., J.S., H.T., and Y.R. have nothing to disclose.

Compliance with Ethics Guidelines. Informed written consent was obtained for the patient to publish the article and their images.

Data Availability. All data generated or analyzed during this study are included in this published article.

Open Access. This article is licensed under a Creative Commons Attribution-NonCommercial 4.0 International License, which permits any non-commercial use, sharing, adaptation, distribution and reproduction in any medium or format, as long as you give appropriate credit to the original author(s) and the source, provide a link to the Creative Commons licence, and indicate if changes were made. The images or other third party material in this article are included in the article's Creative Commons licence, unless indicated otherwise in a credit line to the material. If material is not included in the article's Creative Commons licence and your intended use is not permitted by statutory regulation or exceeds the permitted use, you will need to obtain permission directly from the copyright holder. To view a copy of this licence, visit http://creativecommons.org/licenses/by$\mathrm{nc} / 4.0 /$.

\section{REFERENCES}

1. Chen T, Eichenfield L, Friedlander SJP. Infantile hemangiomas: an update on pathogenesis and therapy. Pediatrics. 2013;131(1):99-108.

2. Munden A, Butschek R, Tom W, Marshall J, Poeltler $\mathrm{D}$, Krohne S, et al. Prospective study of infantile haemangiomas: incidence, clinical characteristics and association with placental anomalies. $\mathrm{Br} \mathrm{J}$ Dermatol. 2014;170(4):907-13.

3. Pope E, Chakkittakandiyil A. Topical timolol gel for infantile hemangiomas: a pilot study. Arch Dermatol. 2010;146(5):564-5.

4. Ran Y, Chen S, Dai Y, Kang D, Lama J, Ran X, et al. Successful treatment of oral itraconazole for infantile hemangiomas: a case series. J Dermatol. 2015;42(2):202-6.

5. Zhu L, Xie J, Liu Z, Huang Z, Huang M, Yin H, et al. Pigment epithelium-derived factor/vascular endothelial growth factor ratio plays a crucial role in the spontaneous regression of infant hemangioma and in the therapeutic effect of propranolol. Cancer Sci. 2018;109(6):1981-94.

6. Chang LC, Haggstrom AN, Drolet BA, Baselga E, Chamlin SL, Garzon MC, et al. Growth characteristics of infantile hemangiomas: implications for management. Pediatrics. 2008;122(2):360-7.

7. Bauland CG, Luning TH, Smit JM, Zeebregts CJ, Spauwen PHM. Untreated hemangiomas: growth pattern and residual lesions. Plast Reconstr Surg. 2011;127(4):1643-8.

8. Pratico AD, Caraci F, Pavone P, Falsaperla R, Drago F, Ruggieri M. Propranolol: effectiveness and failure in infantile cutaneous hemangiomas. Drug Saf Case Rep. 2015;2(1):6.

9. Causse S, Aubert H, Saint-Jean M, Puzenat E, Bursztejn AC, Eschard C, et al. Propranolol-resistant infantile haemangiomas. $\mathrm{Br} \mathrm{J}$ Dermatol. 2013;169(1):125-9.

10. Grant SM, Clissold SP. Itraconazole: a review of its pharmacodynamic and pharmacokinetic properties, and therapeutic use in superficial and systemic mycoses. Drugs. 1989;37(3):310-44. 
11. Del Carratore R, Carpi A, Beffy P, Lubrano V, Giorgetti $\mathrm{L}$, Maserti $\mathrm{BE}$, et al. Itraconazole inhibits HMEC-1 angiogenesis. Biomed Pharmacother. 2012;66(4):312-7.

12. Nacev B, Grassi P, Dell A, Haslam S, Liu JJTJOBC. The antifungal drug itraconazole inhibits vascular endothelial growth factor receptor 2 (VEGFR2) glycosylation, trafficking, and signaling in endothelial cells. J Biol Chem. 2011;286(51): 44045-56.

13. Chen S, Zhuang K, Sun K, Yang Q, Ran X, Xu X, et al. Itraconazole induces regression of infantile hemangioma via downregulation of the plateletderived growth factor-D/PI3K/Akt/mTOR pathway. J Invest Dermatol. 2019;139(7):1574-82.

14. Masand P. Radiographic findings associated with vascular anomalies. Semin Plast Surg. 2014;28(2): 69-78.

15. Mamlouk MD, Nicholson AD, Cooke DL, Hess CP. Tips and tricks to optimize MRI protocols for cutaneous vascular anomalies. Clin Imaging. 2017;45: 71-80. 